\title{
Intravascular ultrasound-guided percutaneous coronary intervention of the left main coronary artery in a 34-year-old patient during cardiopulmonary resuscitation
}

\author{
Jakub Podolec, Bartłomiej Nawrotek, Jacek Legutko \\ Department of Interventional Cardiology, Jagiellonian University Medical College and John Paul II Hospital, Krakow, Poland
}

A 34-year-old patient was admitted to our department with non-ST segment elevation myocardial infarction after pre-hospital syncope followed by chest pain. The patient had a history of poorly controlled hypertension and dyslipidaemia. On admission to the emergency department, the patient had cardiac arrest with pulseless electrical activity. Immediate cardiopulmonary resuscitation (CPR) according to advanced life support guidelines was started. Bedside echocardiography excluded acute tamponade. The patient was transferred to the catheterisation laboratory during mechanical ventilation and cardiac resuscitation with the use of a LUCAS device (Jolife AB/Physio-Control, Lund, Sweden). Continuous intravenous infusions of dobutamine and noradrenaline were administered. Urgent coronarography revealed a massive thrombus in the distal bifurcation of the left main coronary artery (LM) (Fig. 1A, B). After crossing the lesion and securing both the left anterior descending (LAD) and the left circumflex (LCx) arteries with Asahi Sion Blue guidewires (Asahi Intecc, Aichi, Japan), a bail-out

A
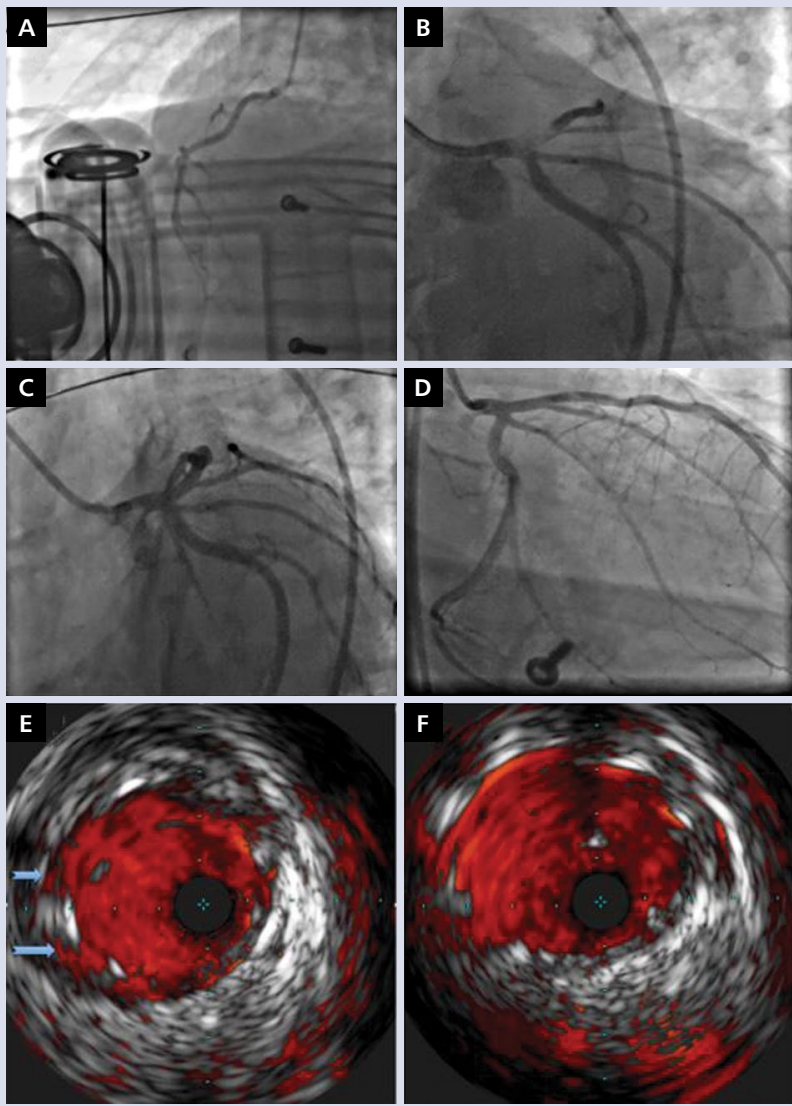

Figure 1. Right coronary artery angiogram during resuscitation with the LUCAS device (A). Left coronary artery with thrombus in the distal left main (LM) and proximal left anterior descending artery during cardiopulmonary resuscitation with the LUCAS device (B). Final angiography (C, D). Intravascular ultrasound post stent implantation: arrows indicate the gap between the stent and the artery wall in the LM (E). Final IVUS of the LM with correct stent positioning $(\mathbf{F})$. bolus of abciximab was administered and aspiration thrombectomy was performed. Sinus rhythm was restored and blood pressure increased to $115 / 80 \mathrm{mmHg}$. CPR was terminated. After restoring the Thrombolysis In Myocardial Infarction grade 3 flow in the LAD and LCX, intravascular ultrasound (IVUS) (Eagle Eye Platinum Digital catheter, Philips, Andover, MA, USA) examination of the LAD and the $L M$ was carried out. It revealed an atherosclerotic plaque with thrombus in the proximal part of the LAD and the distal part of the LM. Percutaneous coronary intervention (PCI) with a 4.0/18 mm Ultimaster stent (Terumo Europe, Leuven, Belgium) covering the proximal LAD and LM was performed, followed by the proximal optimisation technique with a 5.0/8 mm non-compliant (NC) balloon (Fig. 1C, D). Another IVUS examination revealed the need for additional postdilatation with a larger balloon (Fig. 1E). An NC $5.5 / 20 \mathrm{~mm}$ balloon was inflated in the LM with correct stent apposition confirmed by IVUS (Fig. 1F). After the procedure, the patient was admitted to the intensive care unit. A computed tomography scan of the head was performed to exclude mechanical injury and intracranial bleeding. During the first day of hospitalisation the patient was extubated, and dobutamine and noradrenaline were discontinued. After seven days of hospitalisation the patient was transferred to the rehabilitation unit. Left ventricular ejection fraction was $48 \%$ and the patient performed an exercise stress test (17 METs) at the end of the rehabilitation period. After two weeks of hospitalisation the patient was discharged in good clinical condition. $\mathrm{PCl}$ with thrombus aspiration in the setting of acute coronary syndrome (ACS) can be a useful technique in selected patients with large thrombus burden, reducing the risk of no-reflow phenomenon $[1,2]$. Pre- and postprocedural IVUS, even in the acute phase of ACS in a patient with cardiac arrest, is necessary for correct stent positioning in the LM coronary artery [3].

\section{References}

Windecker S, Kolh P, Alfonso F, et al. 2014 ESC/EACTS Guidelines on myocardial revascularization: The Task Force on Myocardial Revascularization of the European Society of Cardiology (ESC) and the European Association for Cardio-Thoracic Surgery (EACTS) Developed with the special contribution of the European Association of Percutaneous Cardiovascular Interventions (EAPCI). Eur Heart J. 2014; 35(37): 2541-2619, doi: 10.1093/eurheartj/ehu278, indexed in Pubmed: 25173339.

2. Ibanez B, James S, Agewall S, et al. 2017 ESC Guidelines for the management of acute myocardial infarction in patients presenting with ST-segment elevation: The Task Force for the management of acute myocardial infarction in patients presenting with ST -segment elevation of the European Society of Cardiology (ESC). Eur Heart 2018: 39(2): 119-177, doi: 10.1093/eurhearti/ehx393, indexed in Pubmed: 28886621.

3. Jang JS, Song YJ, Kang W, et al. Intravascular ultrasound-guided implantation of drug-eluting stents to improve outcome: a meta-analysis. JACC Cardiovasc Interv. 2014; 7(3): 233-243, doi: 10.1016/j.jcin.2013.09.013, indexed in Pubmed: 24529934.

\section{Address for correspondence:}

Jakub Podolec, MD, PhD, Department of Interventional Cardiology, Jagiellonian University Medical College and John Paul II Hospital, ul. Prądnicka 80,

31-202 Kraków, Poland, tel: +48 1261435 01, fax: +48 1261430 47; e-mail: jjpodolec@gmail.com

Conflict of interest: none declared

Kardiologia Polska Copyright @ Polish Cardiac Society 2018 